\title{
Three Phase Induction Motor Control Using Programmable Logic Control With Star Method
}

\section{Kendali Motor Induksi Tiga Fasa Menggunakan Programmable Logic Controller Dengan Metode Star}

\author{
Haris Mastain Arzaq $\left.{ }^{1 *}\right)$, Koko Joni ${ }^{2}$, Riza Alfita ${ }^{3}$, Achmad Ubaidillah ${ }^{4}$ \\ \{Corresponding Author: hrsmstnarzq@ gmail.com $\left.{ }^{1}\right\}$
}

Program Studi Teknik Elektro, Fakultas Teknik, Universitas Trunojoyo Madura

\begin{abstract}
The rapid development of automation system is inseparable from the development of technology in the field of control. In its development, a Programmable Logic Controller (PLC) has been widely used on an industrial scale. PLC programmable can be used as a controller of three phase induction motor. If an error occurs, it can be quickly identified and the work function of each device can be monitored and will also be easier to develop a method of control in the industry. This situation led to many large industries using PLC for all control equipment. In this study created a system of control of three phase induction motor using Programmable Logic Controller (PLC) with the method of Star (Y). Inrush current when the displacement of the position of Star (Y) to Delta (U) is expected to be reduced. The results of the research that has been done the tool can work well and yield value in accordance with the theory. As well as a tool in the design of specialized trainer so it can be used as a learning media.
\end{abstract}

Keywords - 3 Phase Induction Motor; Contactors; Delta (4); PLC; Star (Y)

Abstrak. Pesatnya perkembangan sistem otomasi tidak terlepas dari perkembangan teknologi di bidang kontrol. Dalam perkembangannya, Programmable Logic Controller (PLC) telah banyak digunakan pada skala industri. PLC yang dapat diprogram dapat digunakan sebagai pengontrol motor induksi tiga fasa. Jika terjadi kesalahan, dapat dengan cepat diidentifikasi dan fungsi kerja setiap perangkat dapat dipantau dan juga akan menjadi lebih mudah untuk mengembangkan metode kontrol di industri. Situasi ini menyebabkan banyak industri besar menggunakan PLC untuk semua kontrol peralatan. Pada penelitian ini dibuat suatu sistem kendali motor induksi tiga fasa menggunakan Programmable Logic Controller (PLC) dengan metode Star (Y). Lonjakan arus yang besar saat perpindahan posisi dari Star (Y) ke Delta (4) diharapkan dapat dikurangi. Hasil penelitian yang telah dilakukan alat dapat bekerja dengan baik dan menghasilkan nilai yang sesuai dengan teori. Serta alat di desain berupa trainer sehingga dapat digunakan sebagai media pembelajaran.

Kata Kunci - Delta (4); Kontaktor; Motor Induksi 3 Fasa; PLC; Star (Y)

\section{Pendahuluan}

Di zaman modern saat ini, teknologi berada dalam perkembangan yang sangat pesat. Hampir semua aspek telah merambah dunia digital. Teknologi yang dulunya bekerja secara manual atau konvensional kini menjadi otomatis sepenuhnya. Dalam aspek industri biasanya sebuah pabrik ataupun industri rumah tangga terdapat mesin-mesin yang selalu bekerja untuk dapat memproduksi produk secara banyak [2]. Dalam bidang kontrol, masih banyak dijumpai industri yang menggunakan operator sebagai pengendali sistem secara manual. Namun sistem kontrol manual sering menimbulkan masalah yang disebabkan human error sehingga menghambat proses kontrol [8]. Oleh karena itu sudah banyak industri dan perusahaan besar yang beralih menggunakan sistem otomasi yang lebih mudah penggunaan serta memiliki sedikit resiko sehingga dapat memproduksi secara. Oleh karena itu, dari permasalahan diatas penulis termotivasi untuk membuat suatu sistem pengendali motor induksi dengan metode star menggunakan kontrol PLC. 


\section{METODE}

\section{A. Perancangan perangkat keras}
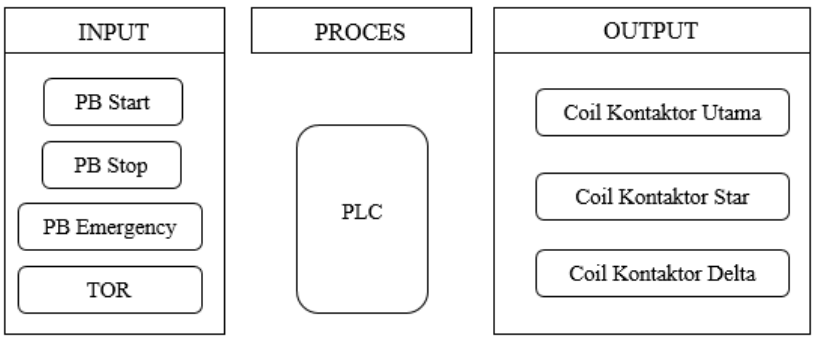

Gambar 1. Blok Diagram

Perangakat keras yang digunakan pada sistem kendali motor induksi tiga fasa menggunakan programmable logic controller (PLC) dengan metode star (Y) terdapat input berupa push button start, stop, emergency, dan thermal overload relay. PLC digunakan sebagai pengolah input sehingga menghasilkan output menuju koil kontaktor.

\section{B. Rangkaian alat}

Rangkaian keseluruhan pada sistem kendali motor induksi tiga fasa menggunakan Programmable Logic Controller (PLC) dengan metode Star (Y) terdiri dari beberapa input dan output. Pengolah data yang digunakan adalah dengan menggunakan PLC. PLC akan memproses input berupa tiga buah push button, yaitu start, stop, emergency, serta input lain dari thermal overload relay sesuai dengan program. Sedangkan output PLC yaitu coil pada setiap kontaktor.

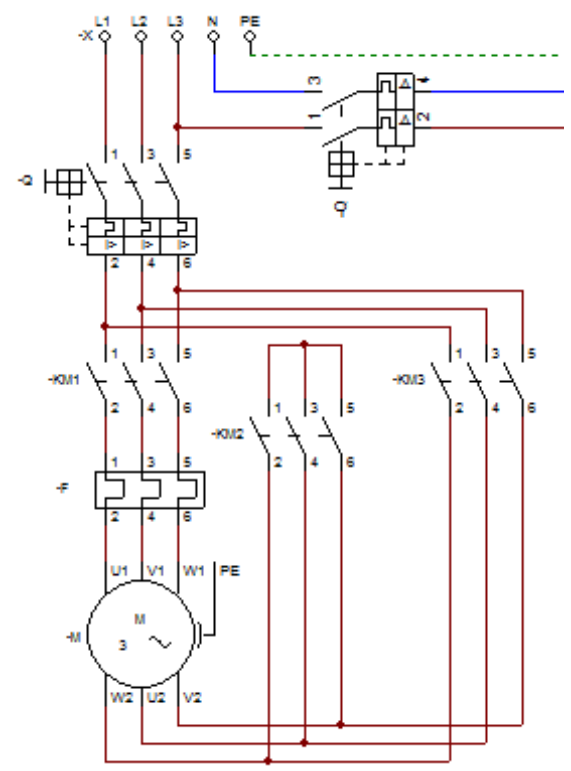

Gambar 2. Rangkaian Daya

Rangkaian daya merupakan jalur tegangan utama motor yaitu tegangan tiga fasa [6]. Dari gambar rangkaian tersebut menggunakan tiga buah kontaktor. Kontaktor utama digunakan sebagai sumber tenaga utama motor untuk mengakses terminal utama, sedangkan 2 kontaktor lainnya digunakan sebagai penghubung star dan delta. 


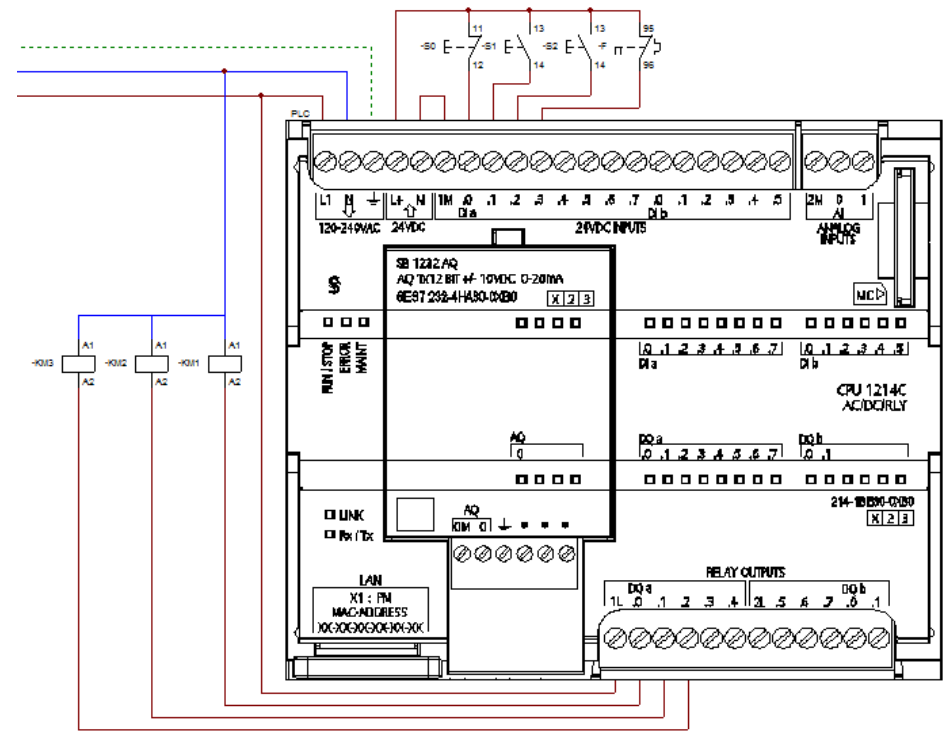

Gambar 3. Rangkaian Kontrol

Rangkaian kontrol merupakan rangkaian satu fasa yang fungsinya untuk mengontrol pengoperasian motor tiga fasa dengan cara memutus atau menghubungkan arus yang mengalir ke motor melalui koil kontaktor [4]. Dari gambar rangkaian kontrol diatas terdapat input kontrol berupa 3 buah push button dan thermal overload relay. Serta plc sebagai unit proses yang outputnya akan memutus atau menyambung aliran arus ke motor melalui coil kontaktornya. Dalam penelitian ini terdapat beberapa komponen utama dan komponen penunjang, berikut daftar dan penjelasan kebutuhan komponen utama yang digunakan:

Motor induksi tiga fasa

Motor induksi tiga fasa adalah motor AC yang paling banyak digunakan sebagai aktuator dalam proses produksi industri untuk mengubah energi listrik menjadi energi gerak untuk berbagai keperluan. Strukturnya yang sederhana dan kokoh adalah alasan penggunaannya secara luas [7]. Namun motor induksi tiga fasa memiliki banyak kekurangan, seperti arus start yang lebih besar dan motor overshoot, kekurangan tersebut akan mempengaruhi kinerja motor induksi yang tidak dapat dipisahkan [1].

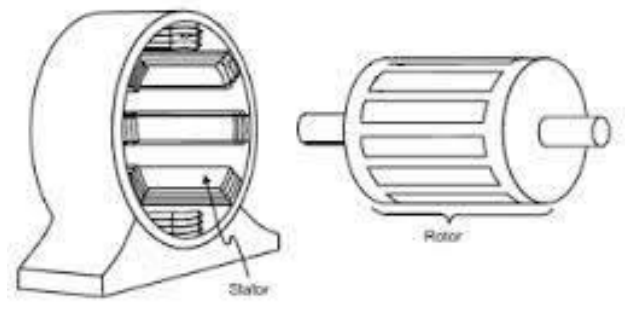

Gambar 4. Stator dan Rotor Motor Induksi Tiga Fasa

Programmable logic controller (PLC)

PLC adalah sebuah perangkat ramah pengguna berbasis mikroprosesor, merupakan komputer khusus yang memuat berbagai jenis dan kompleksitas fungsi kontrol. Ini dapat diprogram, dikendalikan dan dioperasikan oleh orang-orang yang tidak pandai mengoperasikan PC. Operator PLC pada dasarnya menggambar garis dan peralatan dari diagram tangga. Gambar yang dihasilkan komputer menggantikan kabel eksternal yang diperlukan untuk mengontrol proses rangkaian. PLC akan mengoperasikan semua sistem yang membuka atau menutup perangkat keluaran. Itu juga dapat menjalankan sistem apa pun dengan output variabel. PLC dapat dioperasikan dengan perangkat ON-OFF (sakelar) atau perangkat input variabel di sisi input [9]. Pada penilitian ini digunakan PLC Siemens Simatic S7-1200 CPU 1214C AC/DC/RLY. 


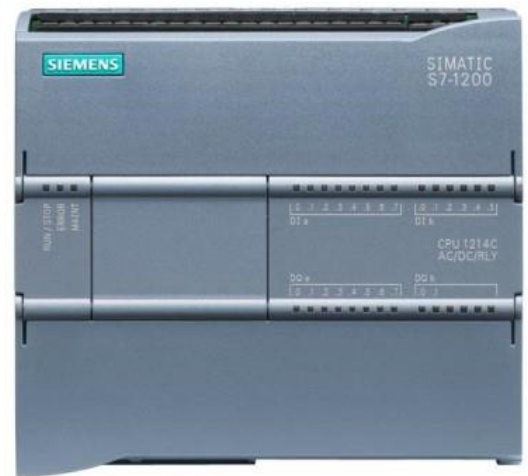

Gambar 5. Programmable Logic Controller (PLC)

\section{Kontaktor}

Kontaktor merupakan salah satu komponen yang dapat digunakan sebagai kontak / kontak berkapasitas besar dengan daya yang minimal. Kontaktor terdiri dari koil, beberapa kontak biasanya terbuka (NO) dan beberapa kontak normal tertutup (NC). Ketika kontaktor normal, NO terputus, dan ketika kontaktor bekerja, NO ditutup. Jika kontak yang biasanya tertutup berlawanan, yaitu, kontak yang biasanya tertutup akan ditutup dalam kondisi normal, dan kontak yang biasanya tertutup akan terbuka dalam kondisi kerja [5]. Kumparan adalah kumparan yang ketika tegangan diberikan, kumparan akan memagnetisasi dan menarik kontak, menyebabkannya berubah atau berfungsi. Kontaktor yang dioperasikan secara elektromagnetik adalah salah satu mekanisme paling berguna yang dirancang sejauh ini digunakan untuk menutup dan membuka sirkuit [3].

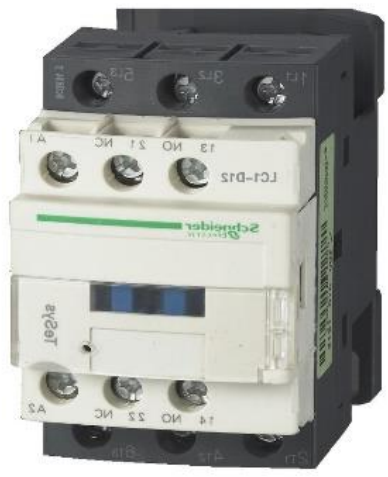

Gambar 6. Kontaktor

\section{Desain perangkat keras}

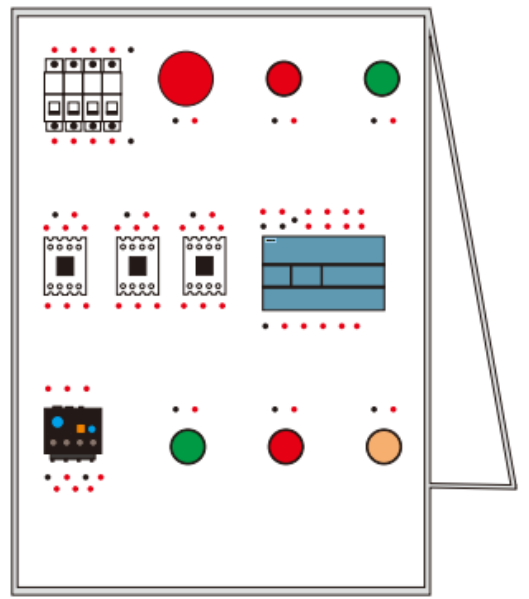

Gambar 7. Desain Alat

Alat di desain berupa trainer sehingga dapat dimanfaatkan sebagai media pembelajaran. Pada trainer terdapat beberapa komponen diantaranya; MCB 3 fasa dan 1 fasa, 3 buah push button, 3 buah kontaktor, 1 buah PLC, 1 buah thermal overload relay, 3 buah lampu indikator, dan terdapat jack banana sebagai penghubung wiring dalam rangkaian. 


\section{Cara kerja alat}

Cara kerja alat dimulai dari mendeteksi apakah push button emergency ditekan atau tidak. Jika emergency ditekan maka motor akan tetap mati, namun jika push button emergency tidak ditekan maka sistem akan mendeteksi apakah overload trip ditekan. Sama dengan push button emergency overload trip juga berfungsi sebagai pengaman, jadi apabila overload trip ditekan maka motor akan mati dan sebaliknya jika tidak ditekan akan lanjut ke proses berikutnya. Selanjutnya sistem mendeteksi apakah push button on ditekan, dan apabila push buttton on ditekan maka motor akan berputar dengan hubungan star. Berikutnya sistem kontrol mendeteksi waktu yang telah di setel pada program timer PLC untuk menentukan waktu yang diperlukan untuk motor berganti menjadi hubungan delta. Untuk proses terakhir yaitu mendeteksi apakah push button Off ditekan, jika tidak maka motor akan tetap berputar sampai push button Off ditekan sehingga motor berhenti.

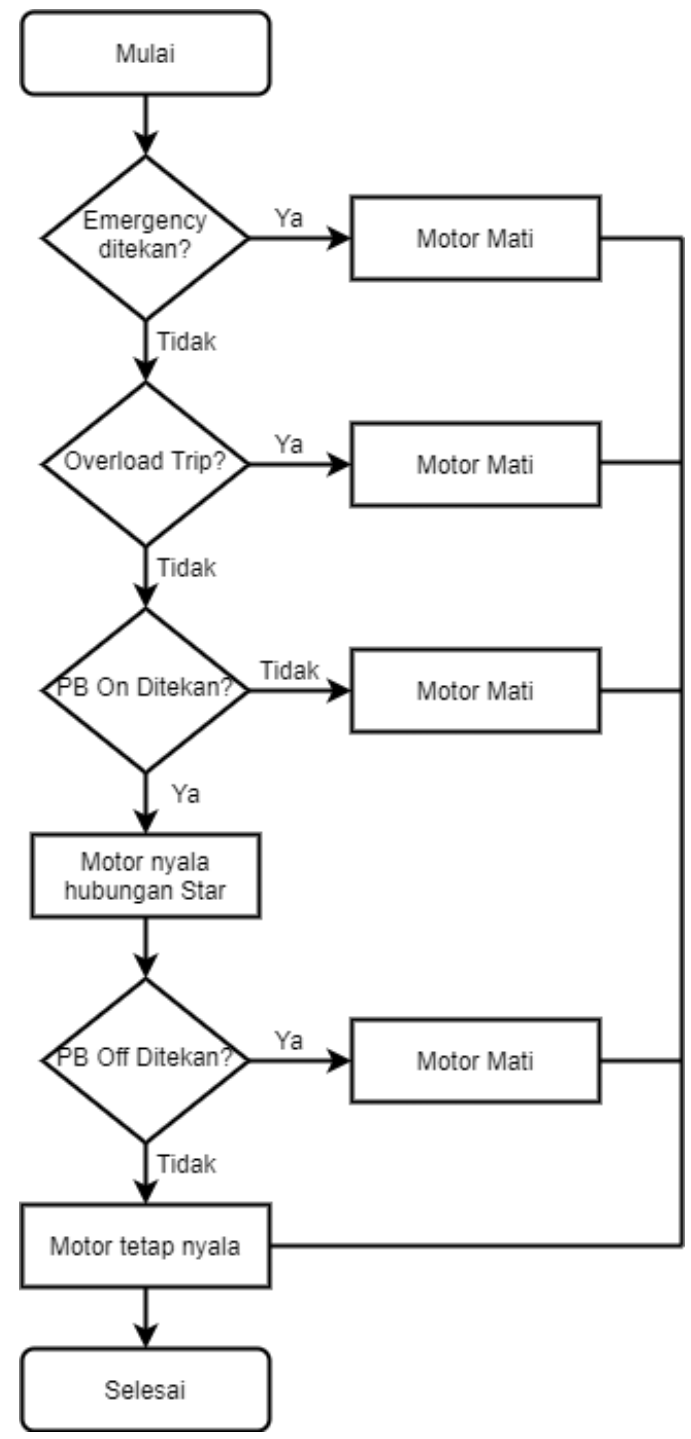

Gambar 8. Flowchart

\section{Hasil dan Pembahasan}

Hasil penelitian sistem ini membahas tentang pengujian secara keseluruhan dari proses pengoperasian hingga hasil yang bertujuan untuk mengetahui kesesuaian hasil. Hasil pengujian seluruh komponen hardware dan software yang telah dilakukan menunjukkan bahwa sistem sudah berjalan sesuai kebutuhan. Untuk mendapatkan data secara keseluruhan dilakukan dengan cara mengukur setiap fasa dengan tang ampere atau clamp meter digital sehingga diketahui nilai lonjakan arus saat start dan nilai arus normalnya. 


\section{A. Percobaan pertama (rangkaian star delta)}

Hasil dari percobaan pertama yaitu nilai lonjakan arus star dan arus normalnya pada rangkaian star delta. Pengujian rangkaian star dilakukan selama 5 detik sebelum rangkaian berubah menjadi rangkaian delta, didapat grafik sebagai berikut:

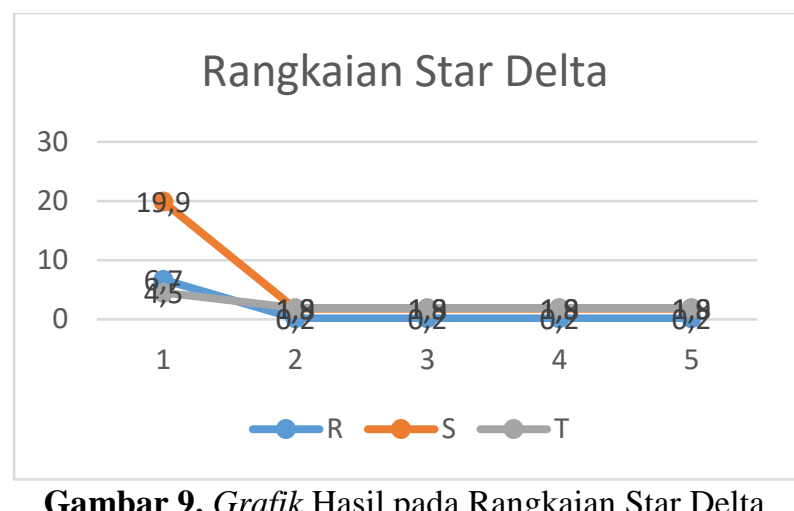

Berdasarkan hasil pengukuran diperoleh lonjakan arus star saat start pada rangkaian star delta beberapa kali lebih besar namun memiliki arus normal yang kecil. Bila di bandingkan dengan lonjakan arus deltanya pasti lonjakan arus delta lebih kecil namun memiliki arus normal yang besar. Karena motor induksi 3 fasa yang dioperasikan dalam belitan delta akan dioperasikan dalam koneksi star dahulu pada awal mula starting.

\section{B. Percobaan kedua (rangkaian star)}

Percobaan kedua yaitu nilai lonjakan arus star dan arus normalnya pada rangkaian star didapat grafik sebagai berikut:

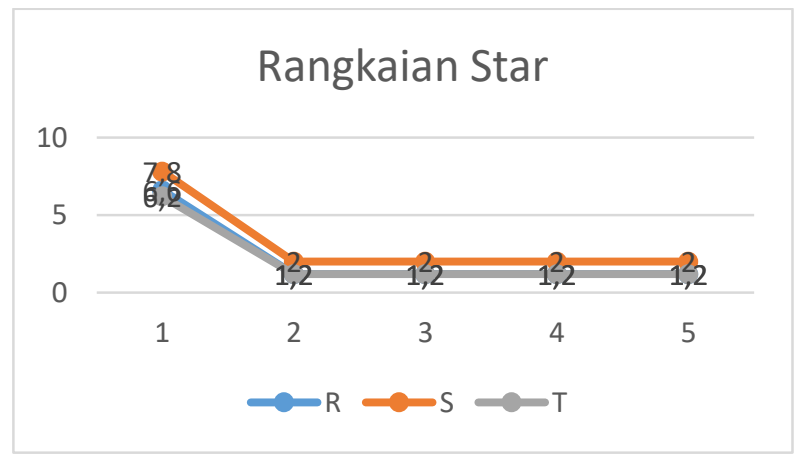

Gambar 10. Grafik Hasil pada Rangkaian Star

Berdasarkan hasil pengukuran, dapat disimpulkan bahwa lonjakan arus bintang saat dihidupkan rangkaian bintang beberapa kali lipat dari arus normal. Namun nilai arus ini akan lebih kecil dari pada nilai lonjakan arus pada rangkaian yang dirangkai delta saja. Karena pada rangkaian star masing masing belitan stator dari motor induksi 3 fasa hanya akan menerima tegangan listrik sebesar tegangan fasa-netral. Tegangan listrik fasa-netral yang lebih kecil dari tegangan fasa-fasa ini akan membuat masing masing fasa motor menarik arus listrik yang lebih kecil pada saat starting. Ini didasarkan pada nilai yang diperoleh dari tegangan fasa netral yang diukur dan tegangan fasa ke fasa. Tabel berikut adalah tabel hasil pengukuran tegangan fasa netral dan tegangan fasa

Tabel 1. Hasil Pengukuran Fasa-Netral

\begin{tabular}{cc} 
Fasa & Fasa-Netral \\
\hline $\mathrm{R}$ & $233 \mathrm{~V}$ \\
\hline $\mathrm{S}$ & $235 \mathrm{~V}$ \\
\hline $\mathrm{T}$ & $231 \mathrm{~V}$
\end{tabular}

Tabel 2. Hasil Pengukuran Fasa-Fasa

\begin{tabular}{cc} 
Fasa & Fasa-Fasa \\
\hline RS & $407 \mathrm{~V}$ \\
\hline RT & $401 \mathrm{~V}$ \\
\hline ST & $405 \mathrm{~V}$
\end{tabular}

Dari hasil pengukuran pada percobaan pertama dan kedua dapat dibuat Tabel sebagai berikut: 
Tabel 3. Hasil Pengukuran Percobaan 1 dan 2

\begin{tabular}{ccccc}
\multirow{2}{*}{ Fasa } & \multicolumn{2}{c}{$\begin{array}{c}\text { Nilai Arus Star } \\
\text { (Rangkaian Star Delta) }\end{array}$} & \multicolumn{2}{c}{$\begin{array}{c}\text { Nilai Arus Star } \\
\text { (Rangkaian Star) }\end{array}$} \\
\cline { 2 - 5 } & $\begin{array}{c}\text { Lonjakan } \\
\text { Arus }\end{array}$ & $\begin{array}{c}\text { Arus } \\
\text { Normal }\end{array}$ & $\begin{array}{c}\text { Lonjakan } \\
\text { Arus }\end{array}$ & $\begin{array}{c}\text { Arus } \\
\text { Normal }\end{array}$ \\
\hline $\mathrm{R}$ & $6,7 \mathrm{~A}$ & $0,2 \mathrm{~A}$ & $6,6 \mathrm{~A}$ & $1,2 \mathrm{~A}$ \\
\hline $\mathrm{S}$ & $19,9 \mathrm{~A}$ & $1,8 \mathrm{~A}$ & $7,8 \mathrm{~A}$ & $2 \mathrm{~A}$ \\
\hline $\mathrm{T}$ & $4,5 \mathrm{~A}$ & $1,9 \mathrm{~A}$ & $6,2 \mathrm{~A}$ & $1,2 \mathrm{~A}$
\end{tabular}

Untuk nilai arus setiap fasa yang berbeda, hal ini bisa disebabkan karena adanya tegangan supply yang didak sama. Ataupun bisa juga disebabkan karena motor yang digunakan dalam pengujian sudah tidak normal.

\section{KESIMPULAN}

Berdasarkan alat dan desain sistem yang lengkap, implementasi dan hasil pengujian, kesimpulan berikut dapat diambil. Pertama hasil perancangan sistem bekerja dengan baik dan menghasilkan nilai yang sesuai dengan teori. Kedua penggunaan PLC sebagai kontrol motor induksi tiga fasa sangat praktis, serta dalam pemrograman dan juga saat mengidentifikasi kesalah yang terjadi. Ketiga alat di desain berupa trainer sehingga dapat digunakan sebagai media pembelajaran. Keempat beberapa hasil nilai pengukuran yang berbeda disebabkan oleh kondisi alat yang yang digunakan dalam pengujian kurang baik.

\section{REFERENSI}

[1] M. T. S. Adlio Dwismara E, Geral Junio R, "KONTROL KECEPATAN MOTOR INDUKSI TIGA FASA MELALUI ARUS ROTOR MENGGUNAKAN PI,” J. Tek. ELEKTRO DAN Komput. TRIAC, vol. 7, no. 2, 2020.

[2] N. Evalina and A. A. Zulfikar, "Pengaturan Kecepatan Putaran Motor Induksi 3 Fasa Menggunakan Programmable Logic Controller," J. Electr. Technol., vol. 3, no. 2, pp. 73-80, 2018.

[3] E. Susanto, “Automatic Transfer Switch (Suatu Tinjauan)," J. Tek. Elektro Unnes, vol. 5, no. 1, pp. 3-6, 2013, doi: 10.15294/jte.v5i1.3549.

[4] I. M. A. N. Sultan, Agung Budi Muljono, "Visualisasi Pengasutan Motor Induksi Tiga Fase Berbasis Programmable Logic Control," vol. 4, no. 1, pp. 58-69, 2017.

[5] I. Journal, F. Technological, A. P. Shinde, K. S. Shendge, and R. K. More, "Plc Automation of Star Delta Starter for Using Induction Motor," vol. 4, no. 9, pp. 1673-1677, 2017.

[6] A. Elbani, "Implementasi Pengendali PLC Pada Sistem Motor Tiga Phasa Untuk Star Y/A," Elkha, vol. 3, no. 1, pp. 18-23, 2011.

[7] H. Istiqlaliyah, "Analisis Pengaruh Penggunaan Sistem Star Delta Dengan Rangkaian Manual Dan Plc Pada Motor Listrik 3 Phasa," Al Jazari J. Mech. Eng., vol. 2, no. 2, pp. 16-21, 2017.

[8] S. Kharait and P. S. Phulambrikar, "Implementation of PLC Based Star Delta Starter for Starting and Direction Control Of Three Phase Induction Motor," vol. 2, no. 11, pp. 2881-2886, 2013.

[9] D. Yuhendri, "Penggunaan PLC Sebagai Pengontrol Peralatan Building Automatis,” J. Electr. Technol., vol. 3, no. 3, pp. 121-127, 2018. 